\title{
Effects of Increasing Metformin Dose vs Adding/ Switching to Dipeptidyl Peptidase-4 Inhibitors on Glycemic Control in Patients with Type 2 Diabetes
}

\author{
Yoshio Nagai · Kiyoyasu Kazumori · Tomomi Takeshima • \\ Kosuke Iwasaki · Yasushi Tanaka
}

Received: December 21, 2020 / Accepted: January 29, 2021 / Published online: February 17, 2021

(C) The Author(s) 2021

\begin{abstract}
Introduction: Metformin has dose-dependent hypoglycemic effects on patients with type 2 diabetes (T2D). In Japan, metformin has been prescribed at lower doses than in Western countries. We analyzed the effect of increasing the metformin dose on glycemic control and compared it to a combination therapy with dipeptidyl peptidase-4 inhibitors (DPP-4i) and a replacement therapy with DPP-4i.

Methods: This is a cohort study using a Japanese claims database. Patients with T2D who had been initially treated with low-dose metformin ( $\geq 500 \mathrm{mg} /$ day and $<1000 \mathrm{mg} /$ day) and then given a prescription change by increasing
\end{abstract}

Supplementary Information The online version contains supplementary material available at https:// doi.org/10.1007/s13300-021-01017-x.

Y. Nagai

Department of Medicine, Metabolism and Endocrinology, St. Marianna University School of Medicine, Kanagawa, Japan

K. Kazumori $(\bowtie)$

Medical Affairs, Sumitomo Dainippon Pharma Co., Ltd., Tokyo, Japan

e-mail: kiyoyasu-kazumori@ds-pharma.co.jp

T. Takeshima $\cdot$ K. Iwasaki

Milliman Inc., Tokyo, Japan

Y. Tanaka

Diabetes Center, Yokohama General Hospital,

Kanagawa, Japan metformin to a higher dose ( $\geq 1000 \mathrm{mg} /$ day) (increased-dose), adding DPP-4i (drug-added), or switching to DPP-4i (drug-switched) were included in this study. The primary outcome was the change in HbA1c levels at 12 months from the baseline period.

Results: Among 2,726,437 patients with T2D, 494 were included. Of these patients, 226, 240, and 28 patients were classified as increased-dose, drug-added, and drug-switched groups, respectively. The HbA1c levels at 12 months from the index significantly decreased compared to that during the baseline period. The change was the highest in the drug-added group (-1.06\%), followed by the increased-dose $(-0.91 \%)$ and the drug-switched groups $(-0.37 \%)$. Among the subset of patients who did not receive any antidiabetic drugs other than metformin or DPP$4 \mathrm{i}$, the highest change in HbA1c levels was observed in the increased-dose group $(-0.84 \%)$, followed by the drug-added $(-0.67 \%)$ and the drug-switched $(-0.42 \%)$ groups. The order of decrease from baseline remained the same for all the study groups after the propensity score weighting adjustment.

Conclusion: The effect on glycemic control when increasing the metformin dose was studied in patients who had been receiving low-dose metformin. Increasing metformin dosage shows effectiveness and could be one of the next treatment options in patients who were prescribed low-dose metformin as the first-line treatment. 
Keywords: Claims database; Combination drug therapy; Dipeptidyl peptidase-4 inhibitors; Dose increased; Drug switch; Glycated hemoglobin A; Glycemic control; Hypoglycemic agents; Metformin; Type 2 diabetes

\section{Key Summary Points}

Why carry out this study?

Metformin has been prescribed at lower doses in patients with type 2 diabetes (T2D) in Japan than those in Western countries despite evidence on its dosedependent hypoglycemic effects

We compared the effect of increasing the metformin dose on glycemic control in patients previously receiving low doses of metformin to that of a combination therapy with dipeptidyl peptidase- 4 inhibitors (DPP-4i) and that of a replacement therapy with DPP-4i by using a Japanese clinical database

\section{What was learned from the study?}

The effect of increasing the metformin dose on glycemic control was similar to that of a combination therapy with DPP$4 \mathrm{i}$ and that of a replacement therapy with DPP-4i

Increasing metformin dosage could be one of the next treatment options in patients who were prescribed low-dose metformin as the first-line treatment

\section{DIGITAL FEATURE}

This article is published with digital features, including a summary slide, to facilitate understanding of the article. To view digital features for this article go to https://doi.org/10.6084/ m9.figshare.13655768.

\section{INTRODUCTION}

Metformin hydrochloride (hereafter referred to as metformin) is reported to have dose-dependent hypoglycemic effects $[1,2]$. According to the medical guidelines of Western countries, metformin is considered as a first-line hypoglycemic drug for the treatment of type 2 diabetes (T2D) [3]. However, metformin, a drug from the biguanide class, has long been prescribed in Japan at doses lower than those prescribed in Western countries. This restriction was introduced because of several consecutive reports in the 1970s on deaths due to lactate acidosis in patients treated with phenformin hydrochloride, which was the first available biguanide [4]. In Japan, the recommended maximum daily dosage of metformin was only $750 \mathrm{mg} /$ day until 2010. Since then, the recommended dosage was increased to 750$1500 \mathrm{mg} /$ day in the maintenance phase of the treatment; a maximum daily dosage of $2250 \mathrm{mg} /$ day was approved. However, despite an increase in the approved maximum daily dose, the average prescribed dose of metformin has been $<1000 \mathrm{mg} /$ day in many patients $[5,6]$. In the pharmacological therapy of diabetes, when the monotherapy of the first-line drug does not achieve adequate glycemic control, the following approaches are considered: increasing the first-line drug dose, switching to other hypoglycemic drugs, or combining the first-line drug with other drugs having different mechanisms of action [7]. If optimal glycemic control is not achieved by the use of metformin as the first-line drug, increasing the metformin dose, combining metformin with dipeptidyl peptidase-4 inhibitors (DPP-4i), or switching to DPP$4 \mathrm{i}$ are generally considered as treatment options $[5,8,9]$.

Several studies have investigated the effect of increasing the metformin dose or administering a combination therapy with DPP-4i for Japanese T2D patients who have not achieved optimal glycemic control while being treated with metformin at low doses $[4,8,10-16]$. Clinical trials have reported the favorable hypoglycemic effects of increasing the metformin dose to > $1000 \mathrm{mg} /$ day [4] and administering a 
combination therapy comprising both metformin and DPP-4i [10-13]. Other studies have been conducted in clinical practices. Using a clinical database, one study investigated the effects of adding DPP-4i to 500-mg/day metformin or increasing the metformin dose [8], Also, observational studies on increasing the metformin dose from $500 \mathrm{mg} /$ day or $750 \mathrm{mg} /$ day to $1000 \mathrm{mg} /$ day [14] and from 1000 to $1500 \mathrm{mg} /$ day [15] for outpatients in a hospital were conducted. To compare the effects between an increased metformin dose and a combination therapy with metformin and DPP$4 \mathrm{i}$, a pilot study of randomized comparative trials was recently conducted, wherein 11 patients receiving $500-1000 \mathrm{mg} /$ day of metformin were divided into two groups: in the first group, the metformin dose was increased to $1500 \mathrm{mg} /$ day; in the second group, a combination therapy of metformin $(750 \mathrm{mg} /$ day $)$ and linagliptin (5 mg/day) was administered [16]. To the best of our knowledge, this study is the first and only clinical trial performed to compare the abovementioned treatments [16]. Considering that metformin has been used at lower doses than the approved dose, and that increasing the metformin dose, combining metformin with DPP-4i, or switching to DPP-4i is usually conducted in patients with insufficient glycemic control, more information comparing the effect among the treatments is required to consider the next possible treatment options.

In the present study, the effect of increasing the metformin dose on glycemic control in patients previously receiving low doses of metformin ( $\geq 500 \mathrm{mg} /$ day and $<1000 \mathrm{mg} /$ day) was compared to that of a combination therapy with DPP-4i and that of a replacement therapy with DPP-4i by using a Japanese clinical database. We expect this study to provide relevant information regarding the appropriate treatment for T2D patients with inadequate glycemic control despite being treated with lowdose metformin as the first-line drug.

\section{METHODS}

\section{Study Design and Data Source}

This is a cohort study based on a Japanese claims database that consisted of data from DPC hospitals from April 2008 to November 2018, as provided by Medical Data Vision Co., Ltd. (MDV database). DPC hospitals are acute hospitals adopting the Diagnosis Procedure Combination/ Per-Diem Payment System (DPC/PDPS) [17]. As of August 2019, the MDV database was comprised of claims data of 28,400,000 patients from 385 hospitals, which accounts for $22 \%$ of acute medical institutions in Japan. Laboratory data were also available for patients from some of the hospitals. Data of all the patients who visited the affiliated DPC hospitals were included regardless of the age and the type of health insurance; however, records of diagnoses and/or treatment received from other medical facilities could not be tracked. The study was approved by the ethics committee of St. Marianna University School of Medicine (4406). As the study only involved analysis of pre-existing data in the databases, written informed consent from the study participants was not required. Clinical trial registration was not required for this study because it was not a prospective study and did not involve any intervention.

\section{Patient Identification}

Patients who met all inclusion criteria and did not meet any exclusion criteria were identified for the analyses in this study (Fig. 1). The inclusion criteria were as follows: (1) patients having records of diagnosis of T2D coded as E11 or E14 by the International Statistical Classification of Diseases and Related Health Problems, 10th revision (ICD10) [18]. In this study, definitive diagnosis, but not suspected diagnosis, was considered as diagnosis. (2) Patients having the first diagnosis of T2D during the observation period. The observation period of each patient was from the first date of any medical practice to the last date of any medical practice in the hospital. Note that the first diagnosis was recorded as "Fromdate" regardless of whether it was before or 


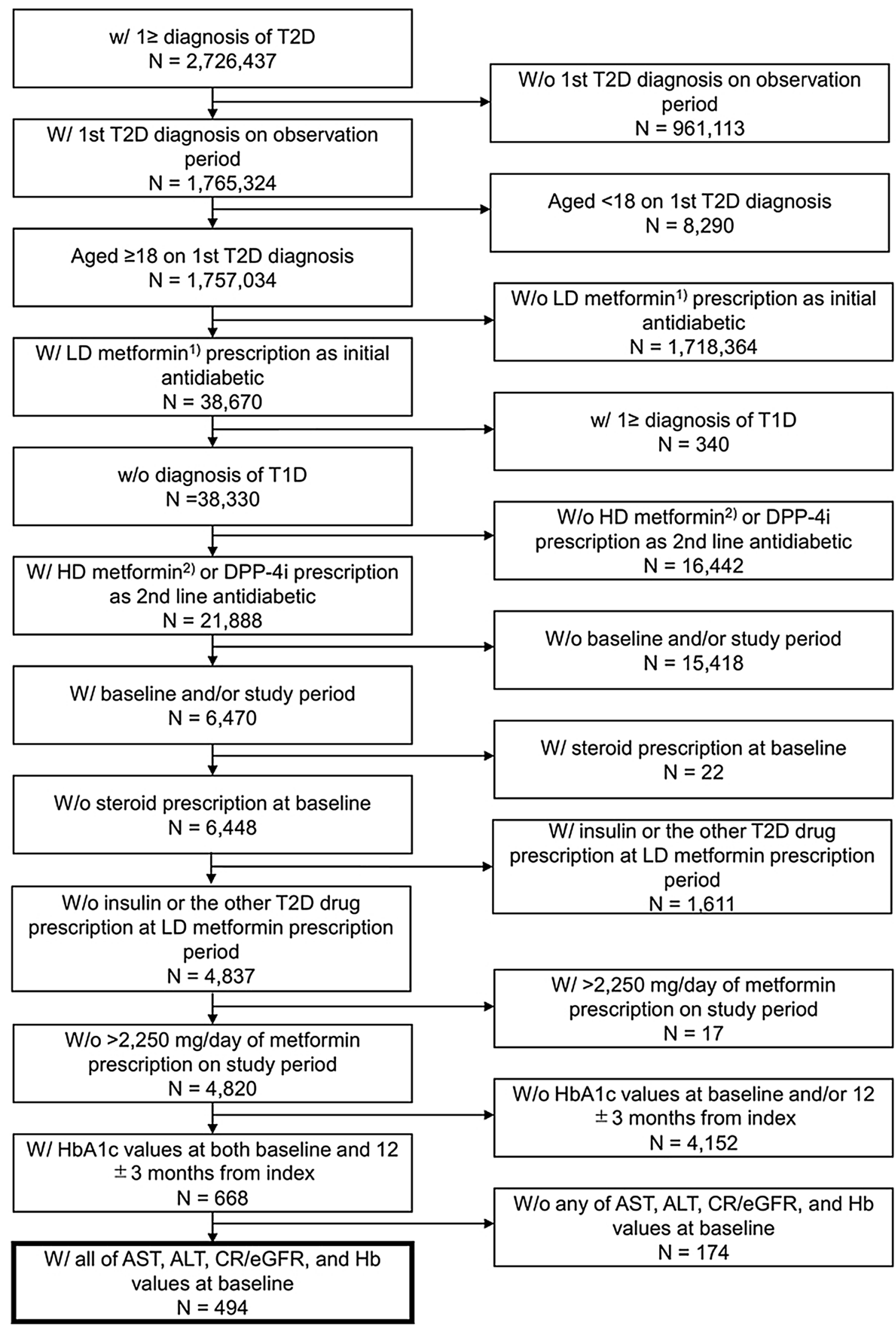


4Fig. 1 Flow chart describing the extraction of target patients for the analysis in this study. (1) LD metformin: prescribed $\geq 500 \mathrm{mg} /$ day and $<1000 \mathrm{mg} /$ day of metformin in the department other than obstetrics or breast surgery. (2) HD metformin: prescribed $\geq 1000 \mathrm{mg} /$ day of metformin. ALT alanine aminotransferase, $A S T$ aspartate aminotransferase, $C R$ creatinine, $D P P-4 i$ dipeptidyl peptidase-4 inhibitor, $e G F R$ : estimated glomerular filtration rate, $H b$ hemoglobin, $H D$ high dose, $L D$ low dose, TID type 1 diabetes, T2D type 2 diabetes, $w /$ with, $w / o$ without

during the observation period in this database. (3) Patients having records of metformin (generic name: metformin hydrochloride) prescription at a dose $\geq 500 \mathrm{mg} /$ day and $<1000 \mathrm{mg} /$ day (defined as low-dose metformin) as the first oral hypoglycemic drug after the first diagnosis of T2D. (4) Patients having records of metformin prescription at a dose of $\geq 1000 \mathrm{mg} /$ day (defined as high-dose metformin) or DPP-4i prescription after the prescription of low-dose metformin. The oldest date of prescription of either highdose metformin or DPP-4i was defined as the index date, and the drug prescribed on the index date (either metformin or DPP-4i) was defined as the index drug. (5) Patients aged $\geq 18$ years old at the first diagnosis of T2D. (6) Patients having $\mathrm{a} \geq 3$-month observation period before the index date. The 3-month period, including the index date, was defined as the baseline period. (7) Patients having $\geq 12$ months of observation period after the index date. The period was defined as the outcome evaluation period. (8) Patients having a laboratory test value of serum glycated hemoglobin A (HbA1c) during the baseline period and at the end of the outcome evaluation period: after 12 months ( \pm 3 months) from the index date. (9) Patients having laboratory test values of aspartate aminotransferase (AST), alanine aminotransferase (ALT), serum creatinine (or estimated glomerular filtration [eGFR]), and hemoglobin ( $\mathrm{Hb}$ ) during the baseline period. The exclusion criteria were as follows: (1) patients having records of type 1 diabetes diagnosis (ICD10 code: E10) during the observation period; (2) patients having prescription records of insulin or other antidiabetic drugs during the period treated with low-dose metformin before the index date; (3) patients having metformin prescription records in the department of obstetrics or breast surgery; (4) patients having records of steroid prescription during the baseline period or the outcome evaluation period; (5) patients having records of metformin prescription at a dose $>2250 \mathrm{mg} /$ day in the outcome evaluation period.

The patients in the primary study group were divided into the following three treatment groups on the basis of index drugs and prescription intervals: (1) increased-dose group: the index drug was high-dose metformin; (2) drugadded group: the index drug was DPP- $4 \mathrm{i}$, and the treatment period prescribed for both lowdose metformin and DPP-4i was $\geq 90$ days; (3) drug-switched group: index drug was DPP-4i, and the treatment period prescribed for both low-dose metformin and DPP-4i was $<90$ days.

The patients for the secondary study group were extracted from each treatment group as follows: (1) increased-dose group: patients with no records of antidiabetic drug prescription other than metformin at an average dose $\geq 1000 \mathrm{mg}$ /day in the outcome evaluation period; (2) drug-added group: patients with no records of antidiabetic drug prescription other than metformin and DPP-4i in the outcome evaluation period, and the average dose of metformin was $<1000 \mathrm{mg} /$ day in the outcome evaluation period; (3) drug-switched group: patients with no records of antidiabetic drug prescription other than DPP-4i in the outcome evaluation period.

\section{Outcome Measures}

The following primary and secondary outcomes were compared between the treatment groups in each study group. The primary outcome was the difference in the HbA1c levels at 12 months ( \pm 3 months) after the index date from that during the baseline period. The secondary outcomes were the difference in the HbA1c levels at 3 months ( \pm 1 months) and 6 months ( \pm 1 months) after the index date from that during the baseline period, the percentage of patients who achieved the target HbA1c level $(6.5 \%$ or $7 \%)$ at 12 months ( \pm 3 months) after the index date, the hospitalization rate (number of hospitalizations divided by the number of patients) during 12 months after the index date, the percentage of patients who developed 
hypoglycemia during 12 months after the index date, and the difference in the levels of highdensity lipoprotein cholesterol (HDL-C), lowdensity lipoprotein cholesterol (LDL-C), total cholesterol (Total-C), triglyceride, AST, ALT, and eGFR at 12 months ( \pm 3 months) after the index date from that during the baseline period.

\section{Statistical Analysis}

We compared each outcome between the treatment groups after confounding factor adjustment was made using the propensity score method. Propensity scores were developed on the basis of the prediction values of logistic regression models. The model was created to predict an order value corresponding to the following order: the increased-dose group, drugadded group, and drug-switched group. In the predictive models, the following explanatory variables were selected as confounding factors for the change in HbA1c: age at index date, sex, clinical test values (HbA1c, AST, ALT, eGFR, and $\mathrm{Hb}$ ) during the baseline period, the existence of diagnosis with diabetic retinopathy during the baseline period, the existence of diagnosis with cancer during the baseline period, the department where patients received metformin prescription just before the index date, the average daily dose of metformin just before the index date, and the calendar year of initial treatment with metformin.

The value of each outcome was calculated for each quintile of the propensity score in each treatment group; then, to evaluate the differences between the groups, the average treatment effect was estimated between two treatment groups. The statistical significance of the difference from baseline and the difference between the groups was evaluated on the basis of the values of $95 \%$ confidence intervals (CI).

We used Microsoft Excel 2010 (Microsoft, Redmond, WA, USA) and SAS version 9.4 (SAS Institute, Cary, NC, USA) for the analyses.

\section{RESULTS}

\section{Patient Characteristics}

Among 2,726,437 patients with T2D, 494 patients were identified and included in the primary study group (Fig. 1). Among these patients, 226 were classified into the increaseddose group, 240 into the drug-added group, and 28 into the drug-switched group (Table1).

Table 1 Patient characteristics in each study group

\begin{tabular}{|c|c|c|c|c|c|c|}
\hline & \multicolumn{3}{|c|}{ Primary study group } & \multicolumn{3}{|c|}{ Secondary study group } \\
\hline & $\begin{array}{l}\text { Increased-dose } \\
\text { group }\end{array}$ & $\begin{array}{l}\text { Drug-added } \\
\text { group }\end{array}$ & $\begin{array}{l}\text { Drug-switched } \\
\text { group }\end{array}$ & $\begin{array}{l}\text { Increased-dose } \\
\text { group }\end{array}$ & $\begin{array}{l}\text { Drug-added } \\
\text { group }\end{array}$ & $\begin{array}{l}\text { Drug-switched } \\
\text { group }\end{array}$ \\
\hline$N$ & 226 & 240 & 28 & 106 & 171 & 14 \\
\hline Age (years) & $54.5 \pm 12.9$ & $61.2 \pm 12.0$ & $64.8 \pm 11.9$ & $56.1 \pm 12.9$ & $62.1 \pm 12.4$ & $62.7 \pm 14.4$ \\
\hline$\%$ Female & 37.6 & 40.4 & 53.6 & 37.7 & 39.2 & 50.0 \\
\hline HbAlc (\%) & $7.76 \pm 1.10$ & $7.94 \pm 1.58$ & $7.56 \pm 1.20$ & $7.62 \pm 1.00$ & $7.49 \pm 1.11$ & $7.66 \pm 1.50$ \\
\hline AST (U/l) & $30.1 \pm 21.4$ & $31.8 \pm 24.7$ & $27.8 \pm 18.1$ & $30.2 \pm 25.4$ & $33.0 \pm 26.4$ & $33.8 \pm 21.9$ \\
\hline $\operatorname{ALT}(\mathrm{U} / \mathrm{l})$ & $40.3 \pm 30.9$ & $35.9 \pm 25.8$ & $31.5 \pm 24.8$ & $38.5 \pm 28.9$ & $36.9 \pm 27.6$ & $39.0 \pm 29.4$ \\
\hline $\begin{array}{l}\text { eGFR }(\mathrm{ml} / \mathrm{min} / \\
\left.1.73 \mathrm{~m}^{2}\right)\end{array}$ & $85.7 \pm 20.0$ & $78.3 \pm 24.8$ & $67.4 \pm 26.7$ & $83.8 \pm 20.3$ & $76.3 \pm 24.3$ & $71.8 \pm 23.6$ \\
\hline $\mathrm{Hb}(\mathrm{g} / \mathrm{dl})$ & $14.5 \pm 1.52$ & $14.2 \pm 1.70$ & $13.1 \pm 2.08$ & $14.5 \pm 1.32$ & $14.2 \pm 1.59$ & $13.0 \pm 2.13$ \\
\hline
\end{tabular}

Mean \pm standard deviation

AST aspartate aminotransferase, $A L T$ alanine aminotransferase, eGFR estimated glomerular filtration, $H b$ hemoglobin 
Table 2 Values of each outcome in each group

\begin{tabular}{|c|c|c|c|c|c|c|}
\hline & \multicolumn{3}{|c|}{ Primary study group } & \multicolumn{3}{|c|}{ Secondary study group } \\
\hline & $\begin{array}{l}\text { Increased- } \\
\text { dose group }\end{array}$ & $\begin{array}{l}\text { Drug-added } \\
\text { group }\end{array}$ & $\begin{array}{l}\text { Drug- } \\
\text { switched } \\
\text { group }\end{array}$ & $\begin{array}{l}\text { Increased- } \\
\text { dose group }\end{array}$ & $\begin{array}{l}\text { Drug-added } \\
\text { group }\end{array}$ & $\begin{array}{l}\text { Drug- } \\
\text { switched } \\
\text { group }\end{array}$ \\
\hline$N$ & 226 & 240 & 28 & 106 & 171 & 14 \\
\hline$\Delta \mathrm{HbAlc} 12 \mathrm{M}(\%)$ & $-0.91^{*}$ & $-1.06^{*}$ & $-0.37^{*}$ & $-0.84^{*}$ & $-0.67^{*}$ & $-0.42^{*}$ \\
\hline$\Delta \mathrm{HbAlc} 3 \mathrm{M}(\%)$ & $-0.83^{*}$ & $-1.08^{*}$ & $-0.55^{*}$ & $-0.85^{*}$ & $-0.86^{*}$ & $-0.43^{*}$ \\
\hline$\Delta \mathrm{HbAlc} 6 \mathrm{M}(\%)$ & $-1.00^{*}$ & $-1.12^{*}$ & $-0.72^{*}$ & $-0.99^{*}$ & $-0.79^{*}$ & $-0.46^{*}$ \\
\hline$\Delta \mathrm{HDL}-\mathrm{C}(\mathrm{mg} / \mathrm{dl})$ & $0.84^{*}$ & 0.28 & 1.55 & 0.57 & 0.24 & 0.70 \\
\hline$\Delta \mathrm{LDL}-\mathrm{C}(\mathrm{mg} / \mathrm{dl})$ & -8.23 & -8.78 & -12.59 & -11.05 & -9.54 & -16.07 \\
\hline$\Delta$ Total-C (mg/dl) & -14.57 & -10.73 & -21.08 & -13.91 & -8.47 & -14.29 \\
\hline$\Delta \mathrm{TG}(\mathrm{mg} / \mathrm{dl})$ & -22.67 & -10.15 & 8.39 & -15.15 & -4.12 & -14.44 \\
\hline$\Delta \mathrm{AST}(\mathrm{U} / \mathrm{l})$ & -2.73 & -2.56 & -3.16 & -2.89 & -2.65 & -8.50 \\
\hline$\Delta \mathrm{ALT}(\mathrm{U} / \mathrm{l})$ & -3.65 & $-5.60^{*}$ & -7.08 & -2.36 & -5.95 & -12.17 \\
\hline $\begin{array}{l}\Delta \mathrm{eGFR}(\mathrm{ml} / \mathrm{min} / \\
\left.1.73 \mathrm{~m}^{2}\right)\end{array}$ & $-1.25^{*}$ & $-4.26^{*}$ & -0.21 & -0.36 & $-2.88^{*}$ & -3.95 \\
\hline HbAlc $<6.5 \%(\%)$ & 33.19 & 36.25 & 28.57 & 29.25 & 33.33 & 35.71 \\
\hline HbAlc < 7.0\% (\%) & 63.27 & 62.08 & 57.14 & 64.15 & 64.33 & 35.71 \\
\hline Hospitalization (\%) & 19.03 & 33.33 & 60.71 & 18.87 & 16.37 & 57.14 \\
\hline
\end{tabular}

$A S T$ aspartate aminotransferase, $A L T$ alanine aminotransferase, $e G F R$ estimated glomerular filtration, $H b$ hemoglobin, $H D L-C$ high-density lipoprotein cholesterol, $L D L-C$ low-density lipoprotein cholesterol, Total-C total cholesterol, $T G$ triglyceride

${ }^{*} 95 \%$ confidence intervals do not cross 0 . The changes in values at 3 months ( \pm 1 months) $(3 \mathrm{M}), 6$ months ( \pm 1 months) $(6 \mathrm{M})$, and 12 months ( \pm 3 months) (12M) from baseline for HbAlc and 12 months ( \pm 3 months) from baseline for other laboratory test values are indicated using delta $(\Delta)$

Among them, 106, 171, and 14 patients corresponded to the increased-dose group, the drugadded group, and the drug-switched group, respectively, in the secondary study group (Table 1).

In the primary study group, the average level of HbA1c during the baseline period was $7.76 \%$ (95\% CI 7.61-7.90\%) in the increased-dose group, $7.94 \%$ (CI 7.74-8.14\%) in the drugadded group, and $7.56 \%$ (CI 7.12-8.01\%) in the drug-switched group. In all the groups, the lower limit of $95 \%$ CI was $>7 \%$. In addition, in the secondary study group, the average level of HbA1c was $7.62 \%$ (CI 7.43-7.81\%) in the increased-dose group, $7.49 \%$ (CI 7.32-7.66\%) in the drug-added group, and $7.66 \%$ (CI $6.88-8.45 \%)$ in the drug-switched group. The increased-dose group had a tendency of lower average age, lower female proportion, and higher eGFR compared to other treatment groups in both study groups (Table 1).

\section{Primary Outcomes}

The average values of the outcomes for each group are listed in Table 2 and Fig. 2, and the average values for each quintile in each group of propensity score are listed in Table S1. The HbA1c levels at 12 months from the index date 
A

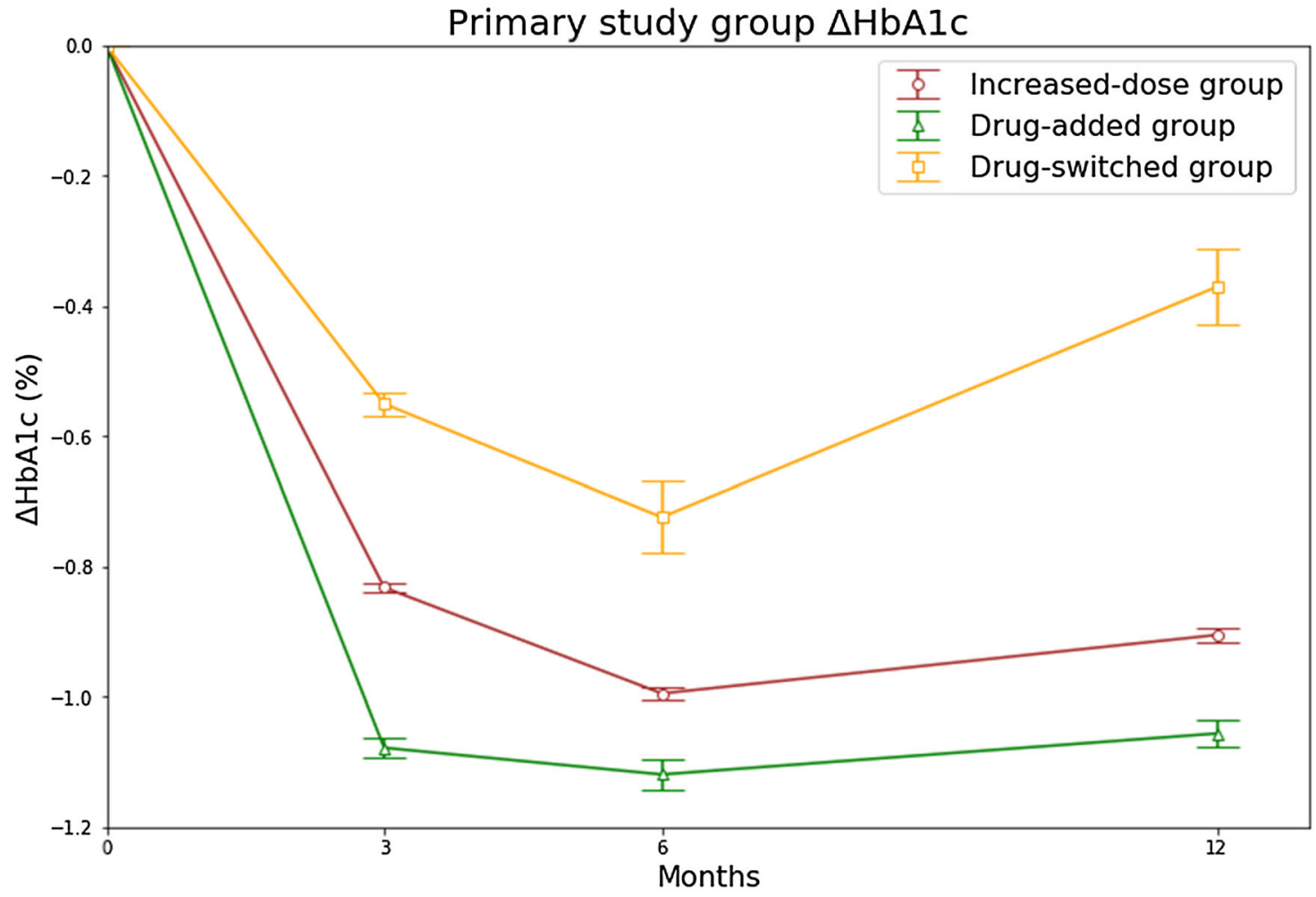

B

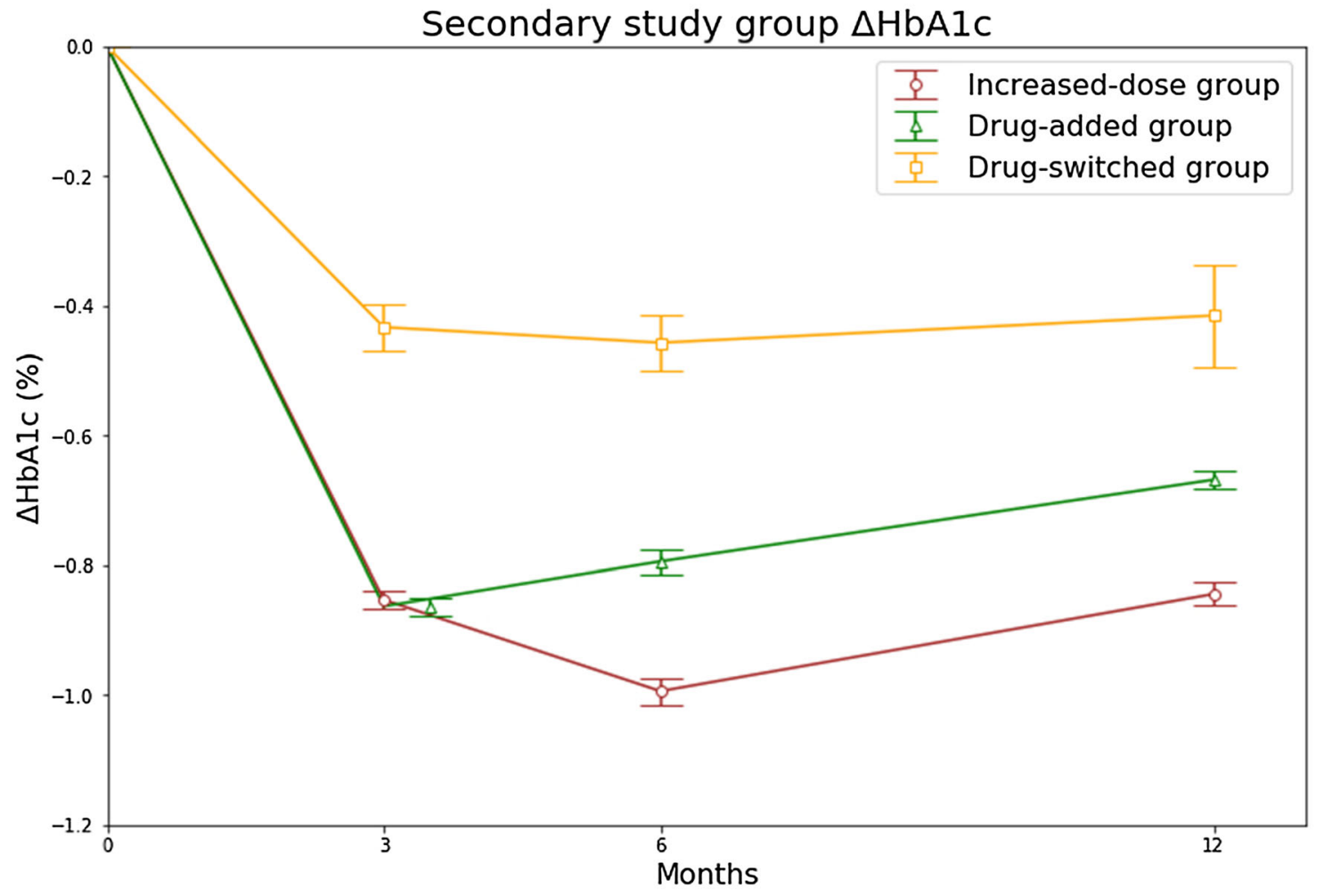


4 Fig. 2 Difference in the HbAlc levels at 3, 6, and 12 months after the index date from that during the baseline period for primary study group (a) and secondary study group (b). Error bars represent 95\% confidence intervals. HbAlc hemoglobin Alc

significantly decreased compared to that during the baseline period in both study groups; the decrease from baseline was largest in the drugadded group $(-1.06 \%)$, followed by the increased-dose group $(-0.91 \%)$ and the drugswitched group $(-0.37 \%)$ in the primary study group, whereas in the secondary study group, the highest decrease was observed in the increased-dose group $(-0.84 \%)$, followed by the drug-added group $(-0.67 \%)$ and the drugswitched group (-0.42\%) (Table 2, Fig. 2). At 12 months from the index date, the average doses of metformin in the primary study group were $938.6 \mathrm{mg} /$ day for the increased-dose group, $521.9 \mathrm{mg} /$ day for the drug-added group, and $91.4 \mathrm{mg} /$ day for the drug-switched group. The average doses in the secondary study group were $1127.6 \mathrm{mg} /$ day for the increased-dose group and $436.7 \mathrm{mg} /$ day for the drug-added group.

The estimated average treatment effect between two groups after propensity score weighting adjustment is given in Table 3 . The order of decrease from baseline remained the same for all the study groups after the weighting adjustment, i.e., drug-added group $>$ increaseddose group $>$ drug-switched group in the primary study group and increased-dose group $>$ drug-added group $>$ drug-switched group in the secondary study group; the differences between the groups were significant in both study groups. In the primary study group, the reduction in the drug-added group was $0.12 \%$ greater than that in the increased-dose group and $0.80 \%$ greater than that in the drug-switched group. The reduction was $1.12 \%$ greater in the increased-dose group than that in the drugswitched group (Table 3). Meanwhile, in the secondary study group, the reduction in the increased-dose group was $0.12 \%$ greater than that in the drug-added group and $0.43 \%$ greater than that in the drug-switched group. The reduction was $0.20 \%$ greater in the drug-added group than that in the drug-switched group (Table 3).

\section{Secondary Outcomes}

In both study groups, the HbA1c levels were significantly decreased in all the treatment groups, both at 3 and 6 months, from the levels obtained during the baseline period (Table 2, Fig. 2). The reduction was largest in the drugadded group $(-1.08 \%)$ at 3 months after the index date in the primary study group, followed by the increased-dose group $(-0.83 \%)$ and the drug-switched group $(-0.55 \%)$. Moreover, at 6 months after the index date, the decrease was greater in the drug-added group $(-1.12 \%)$ than in the increased-dose group (-1.00\%); however, the difference was not significant after the adjustment for confounding factors although the decrease was $0.03 \%$ greater in the drugadded group (Table 3). In both treatment groups, the reduction was greater than that in the drug-switched group $(-0.72 \%)$, and the differences after adjustment for confounding factors were statistically significant (Tables 2,3 ). In the secondary study group, the reduction in the HbA1c levels was greater in the increaseddose group and the drug-added group compared to that in the drug-switched group at both 3 and 6 months after the index date (Tables 2, 3, Fig. 2). At 3 months after the index date, the amount of change in HbA1c levels was comparable between the increased-dose group and the drug-added group (Table 3). At 6 months after the index date, the reduction in HbA1c levels was $0.15 \%$ greater in the increased-dose group than that in the drug-added group, with statistical significance in the secondary study group (Table 3).

Among other clinical test values in the primary study group, a significant increase in HDL$\mathrm{C}$ in the increased-dose group $(0.84 \mathrm{mg} / \mathrm{dl})$ and in ALT in the drug-added group $(-5.60 \mathrm{U} / \mathrm{l})$ and a significant decrease in eGFR in the increased-dose group $\left(-1.25 \mathrm{ml} / \mathrm{min} / 1.73 \mathrm{~m}^{2}\right)$ and the drug-added group $(-4.26 \mathrm{ml} / \mathrm{min} /$ $1.73 \mathrm{~m}^{2}$ ) were observed (Table 2). In the secondary study group, clinical test values did not significantly change other than a significant 
Table 3 Comparison between the groups for each outcome (after adjustment for confounding factors)

\begin{tabular}{|c|c|c|c|c|c|c|}
\hline & \multicolumn{3}{|c|}{ Primary study group } & \multicolumn{3}{|c|}{ Secondary study group } \\
\hline & $\begin{array}{l}\text { Increased- } \\
\text { dose group)- } \\
\text { (drug-added } \\
\text { group) }\end{array}$ & $\begin{array}{l}\text { (Drug-added } \\
\text { group)- } \\
\text { (drug- } \\
\text { switched } \\
\text { group) }\end{array}$ & $\begin{array}{l}\text { (Increased- } \\
\text { dose group)- } \\
\text { (drug-switched } \\
\text { group) }\end{array}$ & $\begin{array}{l}\text { Increased- } \\
\text { dose group)- } \\
\text { (drug-added } \\
\text { group) }\end{array}$ & $\begin{array}{l}\text { (Drug-added } \\
\text { group)- } \\
\text { (drug- } \\
\text { switched } \\
\text { group) }\end{array}$ & $\begin{array}{l}\text { (Increased- } \\
\text { dose group)- } \\
\text { (drug-switched } \\
\text { group) }\end{array}$ \\
\hline $\begin{array}{l}\Delta \mathrm{HbAlc}, 12 \mathrm{M} \\
\quad(\%)\end{array}$ & $0.12^{*}$ & $-0.80^{*}$ & $-1.12^{*}$ & $-0.12^{*}$ & $-0.20^{*}$ & $-0.43^{*}$ \\
\hline $\begin{array}{l}\Delta \mathrm{HbA1c}, 3 \mathrm{M} \\
\quad(\%)\end{array}$ & $0.19^{*}$ & $-0.52^{*}$ & $-0.38^{*}$ & 0.03 & $-0.32^{*}$ & $-0.58^{*}$ \\
\hline $\begin{array}{l}\Delta \mathrm{HbA} 1 \mathrm{c}, 6 \mathrm{M} \\
\quad(\%)\end{array}$ & 0.03 & $-0.46^{*}$ & $-0.42^{*}$ & $-0.15^{*}$ & $-0.23^{*}$ & $-0.58^{*}$ \\
\hline $\begin{array}{l}\Delta \mathrm{HDL}-\mathrm{C}(\mathrm{mg} / \\
\quad \mathrm{dl})\end{array}$ & -0.09 & -1.65 & 0.22 & -0.40 & -0.80 & -0.16 \\
\hline$\Delta \mathrm{LDL}-\mathrm{C}(\mathrm{mg} / \mathrm{dl})$ & 1.56 & 4.29 & -4.86 & -2.47 & 9.01 & -1.60 \\
\hline $\begin{array}{l}\Delta \text { Total-C (mg/ } \\
\quad \mathrm{dl})\end{array}$ & -2.91 & 10.65 & 8.71 & -6.66 & 2.45 & 0.85 \\
\hline$\Delta \mathrm{TG}(\mathrm{mg} / \mathrm{dl})$ & -10.23 & -22.48 & -78.30 & -30.45 & -6.10 & -10.70 \\
\hline$\Delta \mathrm{AST}(\mathrm{U} / \mathrm{l})$ & -0.58 & 1.43 & -1.41 & -3.43 & 7.37 & 0.51 \\
\hline$\Delta \mathrm{ALT}(\mathrm{U} / \mathrm{l})$ & 2.45 & 2.61 & 1.61 & 0.98 & 7.94 & 4.78 \\
\hline $\begin{array}{l}\Delta \mathrm{eGFR}(\mathrm{ml} / \\
\left.\min / 1.73 \mathrm{~m}^{2}\right)\end{array}$ & $4.03^{*}$ & -2.04 & 6.69 & 3.00 & 1.98 & 3.84 \\
\hline $\begin{array}{l}\text { HbAlc }<6.5 \% \\
\quad(\%)\end{array}$ & -1.17 & 1.06 & 7.65 & -3.74 & -14.76 & -1.91 \\
\hline $\begin{array}{l}\text { HbAlc }<7.0 \% \\
\quad(\%)\end{array}$ & 1.90 & -4.97 & 6.91 & 3.84 & 12.81 & $31.00^{*}$ \\
\hline $\begin{array}{l}\text { Hospitalization } \\
\text { (\%) }\end{array}$ & -3.56 & $-36.93^{*}$ & -25.33 & 15.79 & $-66.60^{*}$ & 9.66 \\
\hline
\end{tabular}

$A S T$ aspartate aminotransferase, $A L T$ alanine aminotransferase, $e G F R$ estimated glomerular filtration, $H b$ hemoglobin, $H D L-C$ high-density lipoprotein cholesterol, $L D L-C$ low-density lipoprotein cholesterol, Total- $C$ total cholesterol, $T G$ triglyceride

${ }^{*} 95 \%$ confidence intervals do not cross 0 . The changes in values at 3 months ( \pm 1 months) ( $\left.3 \mathrm{M}\right), 6$ months ( \pm 1 months) $(6 \mathrm{M})$, and 12 months ( \pm 3 months) (12M) from baseline for HbAlc and 12 months ( \pm 3 months) from baseline for other laboratory values are indicated using delta $(\Delta)$

decrease in eGFR in the drug-added group $\left(-2.28 \mathrm{ml} / \mathrm{min} / 1.73 \mathrm{~m}^{2}\right)$ (Table 2$)$. Between the treatment groups, in the primary study group, the reduction in eGFR was statistically significantly greater $\left(4.03 \mathrm{ml} / \mathrm{min} / 1.73 \mathrm{~m}^{2}\right)$ in the drug-added group than in the increased dose group (Table 3 ). In the secondary study group, the percentage of patients achieving HbA1c levels $<7.0 \%$ was greater in the increased-dose group $(64.15 \%)$ than in the drug-switched group (35.71\%) (Table 2), and the difference was $31.00 \%$ and statistically significant after 
adjustment for confounding factors (Table 3). In both study groups, the percentage of hospitalization in the drug-switched group was significantly higher than that in the drug-added group, while other outcomes were comparable between the groups (Table 3). The number of patients who developed hypoglycemia was almost zero in all the treatment groups in both study groups (Table S1B and S1D).

\section{DISCUSSION}

In this study, we aimed to compare the effects of increasing the metformin dose on glycemic control and improvement of other health outcomes to the combination therapy with DPP-4i and the replacement therapy with DPP-4i in patients with T2D who were previously receiving low-dose metformin using a Japanese clinical database. Our results showed that, regarding the glycemic control effect, in all the treatment groups, HbA1c levels decreased at 3 months compared to that during the baseline period. In addition, at 12 months after the index date, the reduction was the largest in the drug-added group, followed by the increased-dose group and the drug-switched group in all the target patients (the primary study group). We found that among those patients who had not received other antidiabetic drugs during the outcome evaluation period (the secondary study group), the reduction in HbA1c levels was the largest in the increased-dose group, followed by the drug-added group and the drugswitched group. For other laboratory test values, we observed an increase in HDL-C in the increased-dose group, a decrease in ALT in the drug-added group, and a decrease in eGFR in both the increased-dose group and drug-added group. When comparing treatment groups, the reduction in eGFR was greater in the drug-added group compared to that in the increased-dose group. Hospitalization rate was higher in the drug-switched group than in the increased-dose group.

We observed that patients who had previously been receiving low-dose metformin showed a hypoglycemic effect at 3 months in all the treatment groups. The improvement in the increased-dose group was greater than that in the drug-switched group, but less than that of the drug-added group. However, the improvement in glycemic control was greater in the increased-dose group than in the DPP4i-added group in the secondary study group where patients did not receive additional antidiabetic drugs. Possibly, in the primary study group, the average dose of metformin in the increaseddose group, which was $938.6 \mathrm{mg} / \mathrm{day}$ at 12 months from the index date, might not have been sufficient to obtain glycemic control at the same levels as that in the drug-added group. Taken together, the effect of increasing the metformin dose on glycemic control may be comparable to that of adding DPP-4i.

When comparing the results in this study to previous studies, we found that the levels of reduction in HbAc1 by adding DPP-4i to lowdose metformin were similar to those in clinical trials, although some differences were observed among the studies, including the patient characteristics, dose of metformin, and DPP-4i, and the type of DPP-4i used in the studies [10-13]. Addition of DPP-4i to low-dose metformin (500-1000 mg/day) has been shown to decrease HbA1c levels to the extent of $0.55-0.64 \%$ [10] or $1.1 \%$ [11] after adding DPP-4i for 12 weeks, $0.8-1.2 \%$ after 14 weeks [13], and $0.49-0.60 \%$ after 24 weeks [12]. In this study, in the drugadded group, where no additional drugs were prescribed, the amount of reduction was $0.86 \%$, $0.79 \%$, or $0.67 \%$ at 3 months, 6 months, or 12 months after the index date, respectively. In clinical studies in real-world settings, the reduction in HbA1c from baseline by increasing the metformin dose from $500 \mathrm{mg} /$ day or $750 \mathrm{mg} /$ day to $1000 \mathrm{mg} /$ day was reported to be $0.65 \% \pm 0.7 \%, \quad 0.87 \% \pm 0.7 \%, \quad$ and $0.42 \% \pm 0.5 \%$ in all the patients, those previously prescribed $500-\mathrm{mg} /$ day or $750-\mathrm{mg}$ /day metformin, respectively, at 6 months from baseline $(8.20 \% \pm 0.68 \%$ of HbA1c) [14]. Our study in patients with an increased metformin dose showed a slightly greater reduction in HbA1c levels, $1.00 \%$ at 6 months after the index date; however, we consider this does not represent a significant different compared with the previous study. In the aforementioned study, the authors also reported that the reduction 
effect was smaller, $0.55 \% \pm 0.62 \%$ from baseline $(8.20 \% \pm 0.68 \%)$, when increasing the metformin dose from 1000 to $1500 \mathrm{mg} /$ day compared with that from 500 to $1000 \mathrm{mg} /$ day [15]. On the other hand, Nishimura et al. analyzed the same database as our study (from January 2011 to December 2015) [8] and reported a change in HbA1c with different prescription statuses at baseline from our study; the metformin dose was limited to $500 \mathrm{mg} /$ day, and prescription of other antidiabetic drugs was allowed. Even given those differences between the two studies, they found a significant decrease in HbA1c at 3 months, similar to our study, and the reduction continued until 12 months after adding DPP-4i or with an increased metformin dose. The amount of decrease they found in HbA1c was $0.2 \pm 0.9 \%$ in the DPP-4i addition group and $0.3 \pm 0.9 \%$ in the increased metformin dose group at 12 months, a decrease smaller than what we found in our study. They also reported that, in the metformin monotherapy patients, no significant decrease in HbA1c was observed when the dose was increased up to $750 \mathrm{mg}$ /day from $500 \mathrm{mg} /$ day, and thus concluded that an increase up to $750 \mathrm{mg} /$ day was not sufficient.

Considering the differences in baseline characteristics among treatment groups, average age was lower in the order of the increaseddose group, drug-added group, and drug-switched group. The eGFR levels were highest in the increased-dose group, followed by the drugadded group and the drug-switched group. In particular, kidney and liver functions are prone to deteriorate in the elderly, and previous studies have indicated that biguanides tend to cause lactic acidosis in aged patients [19-21]. In Japan, aging and a decline in renal function are reported risk factors for lactic acidosis; however, metformin itself is not a risk factor [22]. Our results also suggest that the administration dose of metformin should be determined by considering the characteristics of patients in clinical practice.

In both the increased-dose group and the drug-added group, the eGFR levels decreased and the reduction was greater in the drug-added group than that in the increased-dose group. The eGFR levels during the baseline period were highest in the increased-dose group, followed by those in the drug-added group and then the drug-switched group. The eGFR levels were one of the confounding factors of the propensity score; thus, the eGFR levels will possibly decrease with an increase in the metformin dose or with the addition of DPP-4i. However, for the propensity score adjustment, factors that were assumed to be confounding with the changes in HbA1c, not in eGFR, were selected; therefore, other factors associated with the change in eGFR may not have been adjusted. Moreover, when we stratified the eGFR during the baseline period into predefined classes $(<45 ; \geq 45$ and $<60 ; \geq 60$ and $<90 ; \quad$ and $\geq 90)$, we noticed that the classes over 60 had a decreasing trend, and the class for the range from 45 and $<$ 60 had an increasing trend in all the treatment groups. The differences among the groups were not statistically significant at 12 months from the index date in the primary study group (Table S2). If we consider the possibility of random error, the difference in eGFR during the baseline period between the treatment groups might be reflected in the change level in eGFR at 12 months.

The information on diagnosis and treatment was based on the records in the database, and therefore a possible limitation of this study is that an eventual lack and inaccuracy of the records may affect the preciseness of the results. The MDV database comprised data that were only from DPC hospitals; patients who were treated in clinics and small hospitals were not included. Hence, the patients included in the database may have a more severe disease status of diabetes and/or more comorbidities than the general Japanese patient population with T2D. Furthermore, diagnoses and treatments conducted in other medical facilities were not recorded. Since we had included only those patients with laboratory test values that were available from a limited number of hospitals, the number of samples was relatively restricted, and thus selection bias might need to be taken into account. In addition, we evaluated the efficacy of the treatments in patients who were previously receiving low-dose metformin but the patients were not limited to those who had inadequate glycemic control during low-dose 
metformin treatment. Therefore, patients who changed treatment for reasons other than inadequate glycemic control by low-dose metformin may have been included, and the reasons might differ among different treatment groups. However, in all the treatment groups, the average level of $\mathrm{HbA} 1 \mathrm{c}$ was $>7 \%$, and all the patients had some reason for changing the treatment. Thus, we consider this study is significant for the evaluation of effects on glycemic control in patients whose treatments were changed from their initial treatments with low-dose metformin in clinical practice.

We conducted confounding adjustment for the factors seemingly related to the change in HbA1c levels by using propensity score weighting; however, not all necessary factors might be adjusted because of the limitation of information obtained from database. In addition, the decision to change a prescription may have also been influenced by the advent of new drugs on the market during the treatment period. Therefore, it is important to bear in mind that the results using past data can present some limitations when making changes in the prescription decision process in the future, especially when new drugs may emerge and play a significant role in this decision-making.

\section{CONCLUSION}

The effect on glycemic control when increasing the metformin dose was studied in patients who had been receiving low-dose metformin based on an analysis of a Japanese claims database. The effects of increasing the metformin dosage were similar to those of adding DPP-4i or switching from metformin to DPP-4i. Since in Japan metformin is often used at low doses, the results of our study indicate that increasing the metformin dosage could be one of the next treatment options in patients prescribed metformin in low doses as the first-line treatment.

\section{ACKNOWLEDGEMENTS}

The authors would like to thank to Kenji Baba (Sumitomo Dainippon Pharma Co., Ltd.) for his contribution to the study design.

Funding. Sponsorship for this study and Rapid Service Fee were funded by Sumitomo Dainippon Pharma Co., Ltd.

Medical Writing, Editorial, and Other Assistance. Medical writing was provided by Milliman, Inc., and English language editing was provided by MedPro Clinical Research, which were supported by Sumitomo Dainippon Pharma Co., Ltd.

Authorship. All named authors meet the International Committee of Medical Journal Editors (ICMJE) criteria for authorship for this article, take responsibility for the integrity of the work as a whole, and have given their approval for this version to be published.

Authorship Contributions. Yoshio Nagai, Kiyoyasu Kazumori and Yasushi Tanaka contributed to the study conception. All authors contributed to the study design and interpretation of data. Data analysis was performed by Kosuke Iwasaki. The first draft of the manuscript was written by Tomomi Takeshima, and all authors commented on previous versions of the manuscript. All authors read and approved the final manuscript.

Prior Presentation. Parts of this work were presented at the 63rd Annual Meeting of the Japan Diabetes Society (virtual meeting), October 5-16, 2020.

Disclosures. Yoshio Nagai and Yasushi Tanaka have received speaker's fees from Sumitomo Dainippon Pharma Co., Ltd. Kiyoyasu Kazumori is an employee of Sumitomo Dainippon Pharma Co., Ltd. Tomomi Takeshima and Kosuke Iwasaki are employees of Milliman Inc., which has received consultancy fees from Sumitomo Dainippon Pharma Co., Ltd. 
Compliance with Ethics Guidelines. The study was approved by the ethics committee of St. Marianna University School of Medicine (4406). As the study only involved analysis of pre-existing data in the databases, written informed consent from the study participants was not required. Clinical trial registration was not required for this study because it was not a prospective study and did not involve any intervention.

Data Availability. The data are available from Medical Data Vision Co., Ltd., but restrictions apply to the availability of these data, which were used under license for the current study, and are not publicly available.

Open Access. This article is licensed under a Creative Commons Attribution-NonCommercial 4.0 International License, which permits any non-commercial use, sharing, adaptation, distribution and reproduction in any medium or format, as long as you give appropriate credit to the original author(s) and the source, provide a link to the Creative Commons licence, and indicate if changes were made. The images or other third party material in this article are included in the article's Creative Commons licence, unless indicated otherwise in a credit line to the material. If material is not included in the article's Creative Commons licence and your intended use is not permitted by statutory regulation or exceeds the permitted use, you will need to obtain permission directly from the copyright holder. To view a copy of this licence, visit http://creativecommons.org/licenses/by$\mathrm{nc} / 4.0 /$.

\section{REFERENCES}

1. Garber AJ, Duncan TG, Goodman AM, Mills DJ, Rohlf JL. Efficacy of metformin in type II diabetes: results of a double-blind, placebo-controlled, doseresponse trial. Am J Med. 1997;103:491-7.

2. Fujioka K, Brazg RL, Raz I, et al. Efficacy, dose-response relationship and safety of once-daily extended-release metformin (Glucophage XR) in type 2 diabetic patients with inadequate glycaemic control despite prior treatment with diet and exercise: results from two double-blind, placebo-controlled studies. Diabetes Obes Metab. 2005;7:28-39.

3. Davies MJ, D'Alessio DA, Fradkin J, et al. Management of hyperglycemia in type 2 diabetes. A consensus report by the American Diabetes Association (ADA) and the European Association for the Study of Diabetes (EASD). Diabetes Care. 2018;2018(41): 2669-701.

4. Odawara M, Kawamori R, Tajima N, et al. Longterm treatment study of global standard dose metformin in Japanese patients with type 2 diabetes mellitus. Diabetol Int. 2017;8:286-95.

5. Kameda T, Kumamaru H, Nishimura S, Kohsaka S, Miyata H. Use of oral antidiabetic drugs in Japanese working-age patients with type 2 diabetes mellitus: dosing pattern for metformin initiators. Curr Med Res Opin. 2020;36:749-56.

6. Tamura Y, Kato H, Hiroi S, et al. A study on the prescription status of metformin and DPP-4 inhibitors in patients with type 2 diabetes mellitus in Japan: an analysis data from health insurance administrative claims. Ther Res. 2017;38:1231-7.

7. The Japan Diabetes Society. Clinical practice guideline for diabetes 2019. Tokyo: Nankodo Co., Ltd.; 2019.

8. Nishimura R, Kato H, Kisanuki K, et al. Effectiveness of a dipeptidyl peptidase- 4 inhibitor as add-on therapy to metformin and of dose-escalation of metformin in Japanese patients with type 2 diabetets mellitus in real-world clinical practice settings: a retrospective analysis of a medical information database. Ther Res. 2018;39:325-36.

9. Nishimura R, Kato H, Kisanuki K, et al. Treatment patterns, persistence and adherence rates in patients with type 2 diabetes mellitus in Japan: a claims-based cohort study. BMJ Open. 2019;9: e025806.

10. Seino Y, Miyata Y, Hiroi S, Hirayama M, Kaku K. Efficacy and safety of alogliptin added to metformin in Japanese patients with type 2 diabetes: a randomized, double-blind, placebo-controlled trial with an open-label, long-term extension study. Diabetes Obes Metab. 2012;14:927-36.

11. Odawara M, Hamada I, Suzuki M. Efficacy and safety of vildagliptin as add-on to metformin in Japanese patients with type 2 diabetes mellitus. Diabetes Ther. 2014;5:169-81.

12. Kaku K, Sumino S, Katou M, Nishiyama Y, Kinugawa Y. Randomized, double-blind, phase III study to evaluate the efficacy and safety of once-daily treatment with alogliptin and metformin 
hydrochloride in Japanese patients with type 2 diabetes. Diabetes Obes Metab. 2017;19:463-7.

13. Odawara M, Yoshiki M, Sano M, Hamada I, Lukashevich V, Kothny W. Efficacy and safety of a single-pill combination of vildagliptin and metformin in Japanese patients with type 2 diabetes mellitus: a randomized, double-blind, placebo-controlled trial. Diabetes Ther. 2015;6:17-27.

14. Suzuki K, Yoshioka T, Wakui Y. Quantifying the effect of metformin $1000 \mathrm{mg}$ /day in Japanese patients with type 2 diabetes. Int J Clin Med. 2014;05:894-901.

15. Suzuki K, Mitsuma Y, Anraku T, Kitagawa M, Hasegawa K, Hatta M. A study on efficacy and safety of increasing metformin from 1000 to $1500 \mathrm{mg} /$ day in Japanese patients with type 2 diabetes mellitus. Prog Med. 2017;37:237-43.

16. Takahashi H, Nishimura R, Tsujino D, Utsunomiya $\mathrm{K}$. Which is better, high-dose metformin monotherapy or low-dose metformin/linagliptin combination therapy, in improving glycemic variability in type 2 diabetes patients with insufficient glycemic control despite low-dose metformin monotherapy? A randomized, cross-over, continuous glucose monitoring-based pilot study. J Diabetes Investig. 2019;10:714-22.
17. Ishii M. DRG/PPS and DPC/PDPS as prospective payment systems. Jpn Med Assoc J. 2012;55: 279-91.

18. Ministry of Health, Labor and Welfare. [Statistical classification of diseases and cause of death 2013] (Internet). http://www.mhlw.go.jp/toukei/sippei/. Accessed Nov, 242020.

19. Inzucchi SE, Lipska KJ, Mayo H, Bailey CJ, McGuire DK. Metformin in patients with type 2 diabetes and kidney disease: a systematic review. JAMA. 2014;312:2668-75.

20. DeFronzo R, Fleming GA, Chen K, Bicsak TA. Metformin-associated lactic acidosis: current perspectives on causes and risk. Metabolism. 2016;65:20-9.

21. Salvatore T, Pafundi PC, Marfella R, et al. Metformin lactic acidosis: should we still be afraid? Diabetes Res Clin Pract. 2019;157:107879.

22. Chang $\mathrm{CH}$, Sakaguchi M, Dolin P. Epidemiology of lactic acidosis in type 2 diabetes patients with metformin in Japan. Pharmacoepidemiol Drug Saf. 2016;25:1196-203. 